\title{
Time budgets of finishing bulls housed in an uninsulated barn or at pasture
}

\author{
Leena Tuomisto $^{1}$, Jaakko Mononen², Paula Martiskainen², Leena Ahola ${ }^{2}$ and Arto Huuskonen ${ }^{1}$ \\ ${ }^{1}$ Natural Resources Institute Finland (Luke), Green Technology, FI-92400 Ruukki, Finland \\ ${ }^{2}$ University of Eastern Finland, Department of Biology, FI-70211 Kuopio, Finland \\ e-mail: arto.huuskonen@luke.fi
}

\begin{abstract}
This study aimed at comparing the behaviour of finishing bulls raised in an uninsulated barn (UB) and at pasture (PAS). In experiment 1, dairy bulls were housed in an uninsulated barn (two groups of five bulls, $32 \mathrm{~m}^{2} /$ pen) or at pasture (groups of four and five bulls, $5000 \mathrm{~m}^{2} /$ paddock). In experiment 2, Hereford bulls were housed in an uninsulated barn (three groups of four or five bulls, $32 \mathrm{~m}^{2} /$ pen) or at pasture (three groups of five bulls, $5000 \mathrm{~m}^{2} / \mathrm{pad}$ dock). There were no differences in drinking, social licking, butting, other social behaviour, self-licking or idling between the UB and PAS bulls. The UB bulls spent more time in lying, ruminating, oral explorative and manipulative behaviour and rubbing and less time foraging and walking than the PAS bulls. The UB bulls performed more social licking and oral manipulation of objects and less mounting than the PAS bulls. These differences resulted most probably from the different feeding regimes and different space allowances.
\end{abstract}

Key words: behaviour, bulls, housing, time budgets

\section{Introduction}

Public concern about animal welfare, especially housing conditions, of production animals is increasing (Sørensen et al. 2001). Conventional housing of growing bulls on slatted floors with a low space allowance may compromise the welfare and health of animals in many ways, e.g. by reducing feed intake and daily gain (Ingvartsen and Andersen 1993), increasing abnormal lying down and getting up behaviour (Ruis-Heutinck et al. 2000) and increasing the occurrence of tail tip alterations (Schrader et al. 2001). Therefore, there is a need to develop housing systems which are more in accordance with the welfare needs of growing bulls. There already exists some alternative housing systems for growing cattle, e.g. pens with rubber coated slats and year-around outdoor housing in forest paddocks, which may be beneficial for the welfare of the animals (Absmanner et al. 2009, Tuomisto et al. 2009). Studies with female cattle have demonstrated many positive effects of grazing on the animals; at pasture the animals e.g. behave in a more synchronised fashion (O'Connell et al. 1989, Miller and Wood-Gush 1991, Krohn et al. 1992), have fewer agonistic interactions (O'Connell et al. 1989, Miller and Wood-Gush 1991) and exhibit less oral stereotypies (Redbo 1990) than animals housed indoors in close confinement. Furthermore, daily exercise has a positive effect on the health and lying down movements of tied dairy cows (Gustafson 1993, Gustafson and Lund-Magnussen 1995).

In countries with a long grazing season, steers are commonly grazed in extensive beef production systems (e.g. Rueda et al. 2003). In Finland, where male animals are not routinely castrated, it is not common to graze bulls. Based on findings from the late 1970's, bulls have generally been considered as restless grazers with impaired growth at pasture (Nisula and Hakkola 1979). Bulls have also been reported to fight at pasture and break through fences (Nisula and Hakkola 1979). Furthermore, farmers have often the opinion that bulls are difficult to manage and require heavy and expensive constructions. However, a more recent study has shown that heavy fencing constructions are not necessarily needed, and it is possible to use light electric fences for bull calves and bulls at pasture (Martiskainen et al. 2008).

The behaviour of grazed bulls of any age have been scarcely studied (e.g. Kilgour and Campin 1973, Hinch et al. 1982), and detailed data is lacking. Therefore, the objective of the present study was to compare the behaviour of finishing bulls kept at pasture (PAS) and in a conventional uninsulated barn (UB). It was hypothesised that differences between the housing environments will result in differences in the behaviour of the bulls. The uninsulated barn with a bedded lying area was chosen as a reference, because the results of many studies (e.g. Ruis-Heutinck et al. 2000, Schrader et al. 2001) have already indicated that the common housing system, concrete slatted floors, may jeopardise the welfare of bulls. 


\section{Material and methods}

The present study is part of a series of studies investigating the possibilities of pasture as a housing environment for growing bulls. Results for feed quality, animal performance, carcass characteristics and meat quality have been reported in detail earlier by Huuskonen et al. (2010a, 2010b). In the present paper we focus on the time budgets of finishing dairy and beef bulls kept at pasture and in a conventional uninsulated barn.

\section{Animals and experimental procedure}

The present study was carried out once with dairy-breed and once with beef-breed bulls and was carried out during the summer months (June-August) when the weather conditions in Finland allow grazing. The experiments were conducted at the research station of Natural Resources Institute Finland (Luke) (formerly MTT Agrifood Research Finland) in Ruukki $\left(64^{\circ} 44^{\prime} \mathrm{N}, 25^{\circ} 15^{\prime} \mathrm{E}\right)$ in 2004 and 2005 . Animals were managed according to the Finnish legislation regarding the use of animals in scientific experimentation.

In experiment 1 (Exp 1, 2004), 20 dairy (16 Finnish Ayrshire and four Holstein-Friesian) bulls were used. The bulls were purchased in spring as calves from local dairy farms. At the research station, the calves were housed in an insulated barn until 10 weeks of age and were then transferred to an uninsulated barn. The calves were randomly (balanced for breed) allotted to groups (ten calves/group), which were then randomly allotted to treatments and housed either at pasture or in an uninsulated barn during their first summer, as described in detail in Martiskainen et al. (2008). In August, both groups of ten animals were randomly split in half forming four groups of five animals, and housed the following winter in an uninsulated barn in group pens each with five animals, and fed grass silage and rolled barley with a mineral and vitamin mixture.

At the beginning of next June when the bulls were $15 \pm 0.2$ (mean \pm SD) months old and weighed $552 \pm 11 \mathrm{~kg}$, one group of four (one bull was excluded from the study due to hoof problems) and another group of five bulls were turned to pasture (PAS) and two groups of five bulls were left in the uninsulated barn (UB). No regrouping of the animals was done after the groups of five animals were formed for the first time. Furthermore, all PAS bulls were turned to pasture as calves and all UB bulls were kept in an uninsulated barn as calves. The grazing season lasted 77 days (from 8 June to 23 August). At the end of the experiment, all bulls were slaughtered.

In experiment 2 (Exp 2, 2005), 29 Hereford bulls were used. The bulls born in spring spent their first summer at pasture with their dams. In October, the bulls were divided into five groups of five bulls and one group of four bulls according to their live weight. The following winter, all the bulls were kept in group pens in an uninsulated barn and fed grass silage, rolled barley, and barley fibre with a mineral and vitamin mixture. At the beginning of next June when the bulls were $14 \pm 0.5$ months old and weighed $528 \pm 17 \mathrm{~kg}$, three randomly selected groups of five bulls were moved to pasture paddocks and three groups (two groups of five bulls and one group of four bulls) were left in the uninsulated barn. The grazing season lasted 62 days (from 1 June to 1 August). At the end of the experiment, all bulls were slaughtered.

\section{Housing environments and feeding}

In Exp 1 and 2, the UB bulls were kept in an uninsulated barn in adjacent group pens $\left(4 \times 8 \mathrm{~m}, 6.4-8.0 \mathrm{~m}^{2}\right.$ per bull). The barn was covered with a roof and had solid walls on three sides. The rear half of the pen comprised a straw and peat-bedded lying area. The front half of the pen was a feeding area with a solid concrete floor. A feeding trough was situated in the front side of the pen, and there was $3.5 \mathrm{~m}$ feeding space at the trough (0.7-0.9 m per bull). Water was offered from a water tank located between two pens (Exp 1) or from a water bowl in each pen (Exp 2). The floor of the feeding area was cleaned three times a week and the bedded lying area was cleaned monthly, but fresh bedding was added three times a week.

In Exp 1, both pasture groups were rotationally grazed in five paddocks ( 0.5 ha per paddock), three of them growing perennial timothy (Phleum pratense) and two growing an annual oat (Avena sativa) and Italian rye-grass (Lolium multiflorum) mixture. The animals were moved to a new paddock once a week. A portable water tank and a feeding trough ( $2.5 \mathrm{~m}$ feeding space, $0.5-0.6 \mathrm{~m}$ per bull) were moved from paddock to paddock with the animals. The paddocks were situated so that the PAS bulls could not see each other. 
In Exp 2, the three pasture groups rotationally grazed six paddocks ( 0.34 ha per paddock) growing perennial timothy. The animals were moved to a new paddock once a week, and watered and fed $(2.5 \mathrm{~m}$ feeding space, $0.5 \mathrm{~m}$ per bull) as described in Exp 1. The paddocks were situated in such a way that the pasture groups could see each other. However, the animals in different pasture groups were not able to touch each other because there was always an empty paddock between the groups.

In Exp 1 and 2, the UB bulls received grass silage ad libitum which was given three times a day (at 0600, 1200 and 1800 hours). For concentrate supplementation both the UB and PAS bulls received $4.4 \mathrm{~kg}$ dry matter (DM) rolled barley per animal $\mathrm{d}^{-1}$. The daily concentrate supplementation also included $150 \mathrm{~g}$ of mineral mixture per animal. Concentrate supplementation was given two times a day (at 0600 and 1800 hours). A vitamin mixture was given at $50 \mathrm{~g}$ per animal weekly. The chemical and nutritional compositions of the feeds are fully described by Huuskonen et al. (2010a, 2010b).

\section{Behavioural observations}

In Exp 1 and Exp 2 the behaviour of the UB and PAS bulls was observed for a period of 24 hours (0000-2400 hours) in June and July. The first observation was conducted at week three and the second observation at week seven, counting from the beginning of the grazing season. During observations the PAS bulls grazed on annual oat and Italian rye-grass mixture paddocks (Exp 1$)$ and perennial timothy paddocks (Exp 2). In Exp 1, during the observations, the maximum air temperatures were +19.0 and $+21.4{ }^{\circ} \mathrm{C}$, minimum air temperatures +8.9 and $+8.3^{\circ} \mathrm{C}$, mean air temperatures +15.1 and $+16.2^{\circ} \mathrm{C}$ and average rainy hours 1.3 and 0.0 in June and July, respectively. In Exp 2, during the observations, the maximum air temperatures were +24.5 and $+25.5^{\circ} \mathrm{C}$, minimum air temperatures +4.1 and $+4.1{ }^{\circ} \mathrm{C}$, mean air temperatures +15.4 and $+16.4{ }^{\circ} \mathrm{C}$ and average rainy hours 0.2 and 0.6 in June and July, respectively. The exact days for observations in Exp 2 were chosen so that the weather conditions would be as similar to Exp 1 as possible, since particularly rain is known to affect behaviour of cattle (Hinch et al. 1982).

The bulls were observed using instantaneous sampling (Martin and Bateson 1993) with a 6-min sampling interval. At each sample point each bull was scanned and the posture and activity of the bull were registered according to a classification presented in Table 1. In order to achieve more precise information on the bulls' social and potentially abnormal activities, a 2-min period of one-zero sampling (Martin and Bateson 1993) was carried out between the sample points of the instantaneous sampling.

Table 1. Description of postures and activities recorded during instantaneous sampling observations

\begin{tabular}{|c|c|}
\hline Behaviour & Description \\
\hline Lying total & Lying in any position with trunk in contact with ground. \\
\hline Eating feed at the feeding trough & Eating and masticating silage or barley at the feeding trough. \\
\hline Grazing & Walking, taking bites and masticating grass at the pasture. \\
\hline Foraging total & Eating feed at the feeding trough and grazing. \\
\hline Drinking & Drinking water from the bowl. \\
\hline Ruminating & Chewing cud in any position. \\
\hline Oral explorative and manipulative behaviour & $\begin{array}{l}\text { Licking, gnawing or sniffing any structures in the barn or pasture. Eating and } \\
\text { masticating bedding at the lying area or soil at the pasture. }\end{array}$ \\
\hline Social licking & Licking another bull. Being licked by another bull. \\
\hline Butting & $\begin{array}{l}\text { Butting or pushing another bull with forehead in playful or aggressive way. Being } \\
\text { butted by another bull. }\end{array}$ \\
\hline Other social behaviour & $\begin{array}{l}\text { Social behaviour excluding social licking and butting, e.g. sniffing another animal, } \\
\text { forcing another animal to stand up, mounting and other sexual behaviour } \\
\text { (guarding, chin resting, flehmen) and challenging (pawing ground, rubbing } \\
\text { against ground). }\end{array}$ \\
\hline Walking & Walking without grazing. \\
\hline Rubbing & Rubbing own body against any equipment. \\
\hline Licking & Touching own body with tongue. \\
\hline Standing idling & Standing without any apparent activity. \\
\hline Lying resting & $\begin{array}{l}\text { Lying without any apparent activity in any position with trunk in contact with } \\
\text { ground. Sleeping. }\end{array}$ \\
\hline Tongue-rolling & $\begin{array}{l}\text { Twisting and twirling the tongue, either inside or outside the open mouth for } \\
\text { at least } 5 \text { seconds. }\end{array}$ \\
\hline
\end{tabular}


PAS bulls in both experiments and UB bulls in Exp 2 were observed directly from an observation tower (height 2.5 meters) that was placed in front of the uninsulated barn or paddocks. In Exp 1 the behaviour of the UB bulls was video-recorded using two wide-angle lens cameras per pen and a time-lapse recorder. All observations (i.e. in live situations and from video-tapes) were made by three experienced observers. While doing paddock observations they took turns of 4-6 hours, and used binoculars whenever needed to confirm the observations. No additional light was needed as day light allowed visual observations to be done throughout the night.

Table 2. Description of postures and activities recorded during one-zero sampling observations

\begin{tabular}{ll}
\hline Behaviour & Description \\
\hline Licking another animal & Licking another bull. \\
Butting & Butting or pushing another bull with forehead. \\
Mounting & Mounting another bull's body or head from front, side or back. \\
Manipulating objects & Licking and gnawing any structures in the barn or pasture. \\
Tongue rolling & Twisting and twirling the tongue, either inside or outside the open mouth \\
& for at least 5 seconds. \\
\hline
\end{tabular}

During each one-zero sampling period the bulls were continuously observed and the behaviour patterns described in Table 2 were recorded. It has been suggested that one-zero sampling is a practical method for recording intermittent behaviour that starts and stops repeatedly and rapidly, and lasts only briefly on each occasion (Martin and Bateson 1993), such as social interactions and abnormal behaviours of brief duration.

\section{Statistical analyses}

The data were subjected to analysis using the SAS MIXED procedure (version 9.3, SAS Institute Inc., Cary, NC). Selected statistical model was based on a fact that several animals are housed together within a pen/paddock. In the model the experimental unit was the group of animals to which the housing environment treatment was applied. Observations were measured from all animals, but between-animal variation was not used as an error term. Measurements were taken two times from all animals. Measurement time was included as a repeated factor in the statistical model. The linear mixed model was:

$$
Y_{i j k l m}=\mu+\beta_{i}+\gamma_{j}+\beta \gamma_{i j}+\phi_{i j l}+\theta_{k}+\beta \theta_{i k}+\gamma \theta_{j k}+\theta \phi_{j i k l}+\varepsilon_{i j k l m}
$$

where $\mathrm{i}=1,2$ (experiment), j = 1, 2 (housing environment), $\mathrm{k}=1,2$ (month), $\mathrm{l}=1,2,3$ (two or three groups per housing environment per experiment), $m=1,2,3,4,5$ (four or five animals per group). $Y_{\mathrm{ijklm}}$ is the dependent variable of the $\mathrm{m}^{\text {th }}$ animal in the $\mathrm{i}^{\text {th }}$ experiment, the $\mathrm{j}^{\text {th }}$ housing environment, the $\mathrm{k}^{\text {th }}$ month and the $\mathrm{I}^{\text {th }}$ group. $\mu$ is the general mean, $\beta_{i}$ is the effect of the $i^{\text {th }}$ experiment, $\gamma_{j}$ is the effect of the $j^{\text {th }}$ housing environment, $\beta \gamma_{i j}$ is the effect of interaction between the $\mathrm{i}^{\text {th }}$ experiment and the $\mathrm{j}^{\text {th }}$ housing environment, $\phi_{\mathrm{ijl}}$ is the random effect of $\mathrm{I}^{\text {th }}$ group within the environment-by-experiment combination. All the above effects constitute the between-animal part of the model. The other effects are within-animal part of the model and take into account repeated measures: $\theta_{k}$ is the effect of the $k^{\text {th }}$ month, $\beta \theta_{i k}$ is the effect of interaction between the $i^{\text {th }}$ experiment and the $k^{\text {th }}$ month, $\nu \theta_{j k}$ is the effect of interaction between the $j^{\text {th }}$ housing environment and the $k^{\text {th }}$ month and $\theta \phi_{i j k l}$ is the random effect of interaction between the $\mathrm{k}^{\text {th }}$ month and $\mathrm{I}^{\text {th }}$ group within the environment-by-experiment combination. Finally, $\varepsilon_{\mathrm{ij} k \mathrm{~m}}$ is the residual error and $\theta_{\phi i \mathrm{jl} l}$ is the error term for statistical tests, not $\varepsilon_{\mathrm{ijk} / \mathrm{m}}$.

The model took into account the fact that residuals from the same animal are not correlated. The covariance matrix (compound symmetry structure or heterogeneous compound symmetry structure) for repeated measurements was selected using Akaike's information criteria. The normality of residuals was checked for each analysis using graphical methods: box-plot and scatter plot of residuals and fitted values. If needed, the variable $(x)$ was $\ln (x+1)$ or Box-Cox (Box and Cox 1964) transformed. All the estimates presented have been transformed back to the original scale. Tukey's test was used in pairwise comparisons. If a constancy of the residual variance was not achieved by transformation, the variable was not tested statistically.

\section{Results \\ Instantaneous sampling observations}

The experiment had no effect on the lying time of the bulls (Table 3). However, the UB bulls spent more time lying than the PAS bulls and the difference in the lying time between the UB and PAS bulls was greater in June (UB bulls $64.0 \%$ of observations and PAS bulls $51.6 \%$ of observations, $p=0.001$ ) than in July (UB bulls $61.7 \%$ of observations and PAS bulls $57.8 \%$ of observations, $p=0.25$ ). Furthermore, the PAS bulls spent less time lying in June than in July (June $51.6 \%$ of observations and July $57.8 \%$ of observations, $p=0.007$ ). 


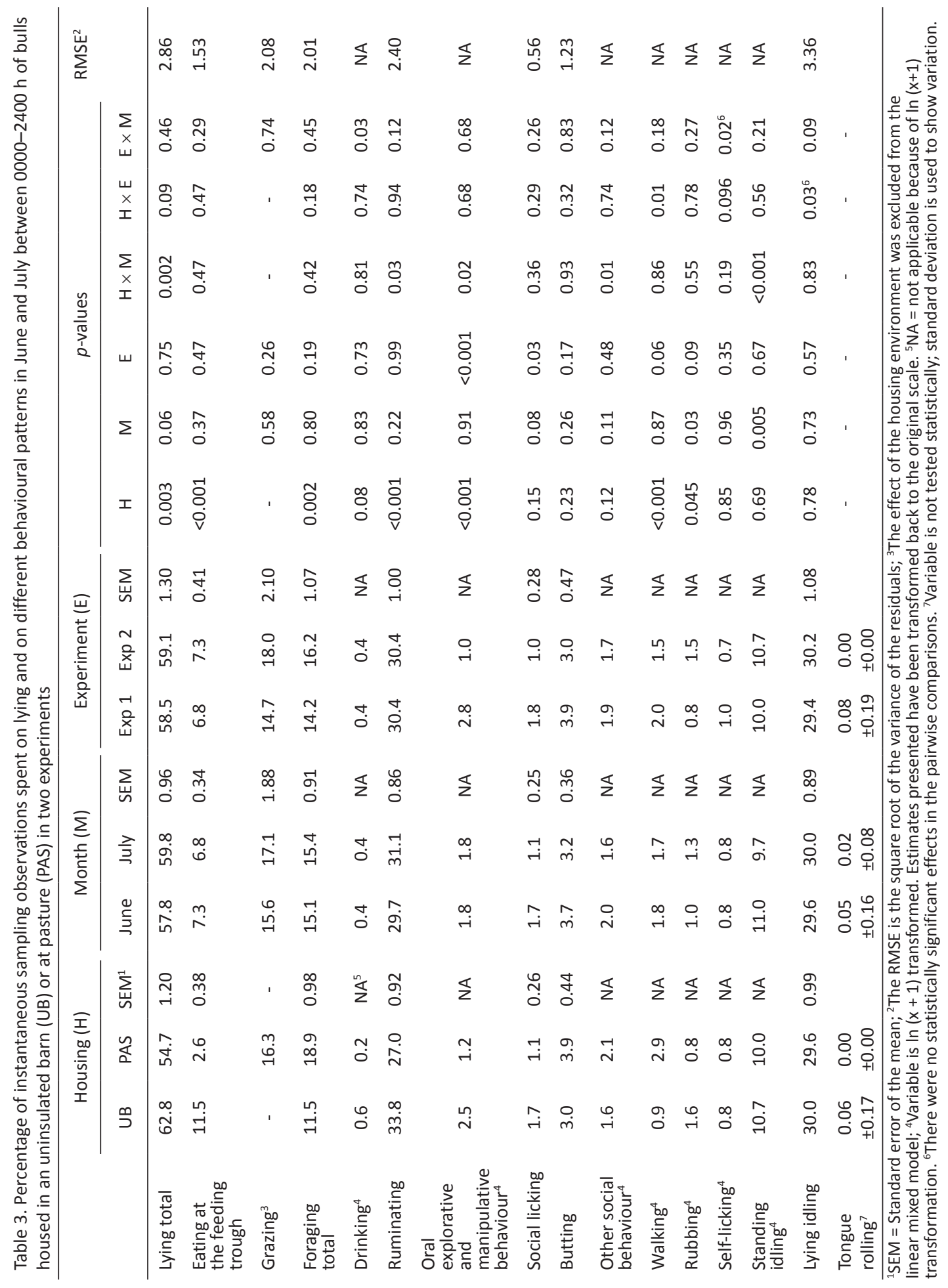


The UB bulls spent more time eating feed at the feeding through than the PAS bulls (Table 3). The month or experiment did not have any effect on the feeding time at the feeding through in the UB and PAS bulls, or grazing time in the PAS bulls. In total, the foraging time was longer for PAS bulls than for UB bulls. The UB bulls tended to spend more time drinking than the PAS bulls. The interaction of the month and the experiment was significant but there were no statistically significant effects in the pairwise comparisons.

The experiment had no effect on the ruminating time of the bulls (Table 3). The UB bulls spent more time ruminating than the PAS bulls and the difference in the ruminating time between the UB and PAS bulls was greater in June (UB $34.5 \%$ of observations and PAS $24.9 \%$ of observations, $p<0.001$ ) than in July (UB $33.2 \%$ of observations and PAS $29.0 \%$ of observations, $p=0.09$ ).

Oral explorative and manipulative behaviour was observed more often in the bulls in Exp 1 than in Exp 2 (Table 3). The UB bulls spent more time performing oral explorative and manipulative behaviour than the PAS bulls and the difference in the time performing oral and manipulative behaviour between the UB and PAS bulls was smaller in June (UB $2.3 \%$ of observations and PAS $1.4 \%$ of observations, $p=0.016$ ) than in July (UB $2.8 \%$ of observations and PAS $1.1 \%$ of observations, $p<0.001)$.

The housing environment had no effect $(p=0.15)$ on the time the bulls performed social licking (Table 3 ). The bulls performed more social licking in $\operatorname{Exp} 1$ than in $\operatorname{Exp} 2(p=0.03)$ and tended to perform more social licking in June than in July $(p=0.08)$. The housing environment, month or experiment had no effect on the time the bulls spent butting. The experiment had no effect on the time the bulls performed other social behaviour (e.g. sniffing another animal, mounting and other sexual behaviour). In June, the UB bulls tended to perform less other social behaviour than the PAS bulls (UB $1.4 \%$ of observations and PAS $2.7 \%$ of observations, $p=0.052$ ). In addition, in the PAS bulls, other social behaviour was observed more often in June than in July (June $2.7 \%$ of observations and July $1.5 \%$ of observations, $p=0.03$ ).

The month had no effect on the walking time of the bulls (Table 3). The UB bulls spent less time walking than the PAS bulls and the difference in the walking time was greater in Exp 2 (UB $0.6 \%$ of observations and PAS 3.1\% of observations, $p<0.001$ ) than in Exp 1 (UB 1.4\% of observations and PAS $2.7 \%$ of observations, $p=0.04$ ). Furthermore, the UB bulls were observed to walk more often in $\operatorname{Exp} 1$ (1.4\% of observations) than in $\operatorname{Exp} 2$ ( $0.6 \%$ of observations) ( $p=0.02)$.

Rubbing was observed more often in the UB bulls than in the PAS bulls and less often in June than in July (Table 3). The bulls tended to rub less in Exp 1 than in the Exp 2. The housing environment had no effect on the time the bulls performed self-licking. The interaction of the month and the experiment was significant but there were no statistically significant effects in the pairwise comparisons.

The experiment had no effect on the time the bulls spent idling in a standing posture. The PAS bulls were observed to idle in a standing posture more in June than in July (June $12.2 \%$ of observations and July $8.1 \%$ of observations, $p<0.001)$. The month had no effect on the time the bulls spent idling in a lying posture. The interaction of the housing environment and the experiment was significant but there were no statistically significant effects in the pairwise comparisons. Stereotyped tongue rolling was very rarely observed and only in the UB bulls in Exp 1.

\section{One-zero sampling observations}

Licking another animal was observed more often in the UB bulls than in the PAS bulls, in June than in July and in Exp 1 than in Exp 2 (Table 4). The housing environment had no effect on butting. The bulls performed more butting in June than in July and tended to perform more butting in Exp 1 than in Exp 2. Mounting was observed more in the PAS bulls than in the UB bulls and in Exp 1 than in Exp 2. The month had no effect on mounting behaviour.

Oral manipulation of objects (licking, gnawing) was observed more often in the UB bulls than in the PAS bulls and in Exp 1 than in Exp 2. The bulls tended to perform more oral manipulation of objects in June than in July. Stereotypic tongue rolling was rarely observed throughout the study. 
L. Tuomisto et al. (2015) 24: 173-182

Table 4. Occurrence of different behavioural patterns as a percentage of all sample intervals during one-zero sampling in June and July between $0000-2400 \mathrm{~h}$ of bulls housed in an uninsulated barn (UB) or at pasture (PAS) in two experiments

\begin{tabular}{|c|c|c|c|c|c|c|c|c|c|c|c|c|c|c|c|c|}
\hline & \multicolumn{3}{|c|}{ Housing $(\mathrm{H})$} & \multicolumn{3}{|c|}{ Month (M) } & \multicolumn{3}{|c|}{ Experiment (E) } & \multicolumn{6}{|c|}{$p$-values } & \multirow[t]{2}{*}{$\mathrm{RMSE}^{2}$} \\
\hline & UB & PAS & SEM $^{1}$ & June & July & SEM & Exp 1 & Exp 2 & SEM & $\mathrm{H}$ & $M$ & E & $\mathrm{H} \times \mathrm{M}$ & $\mathrm{H} \times \mathrm{E}$ & $E \times M$ & \\
\hline $\begin{array}{l}\text { Licking } \\
\text { another } \\
\text { animal }^{3}\end{array}$ & 2.2 & 1.4 & $N A^{4}$ & 2.1 & 1.5 & NA & 2.9 & 0.9 & NA & 0.04 & 0.03 & $<0.001$ & 0.24 & 0.07 & 0.19 & NA \\
\hline Butting & 8.9 & 10.6 & 1.01 & 10.7 & 8.8 & 0.76 & 11.2 & 8.3 & 1.10 & 0.26 & 0.01 & 0.09 & 0.096 & 0.23 & 0.59 & 2.09 \\
\hline Mounting $^{3}$ & 0.7 & 1.6 & NA & 1.2 & 1.0 & NA & 1.9 & 0.5 & NA & 0.004 & 0.35 & $<0.001$ & 0.09 & 0.21 & 0.99 & NA \\
\hline $\begin{array}{l}\text { Manipulating } \\
\text { objects }^{5}\end{array}$ & 1.8 & 0.3 & NA & 1.2 & 0.6 & NA & 2.7 & 0.1 & NA & 0.01 & 0.06 & $<0.001$ & 0.16 & 0.09 & 0.44 & NA \\
\hline $\begin{array}{l}\text { Tongue } \\
\text { rolling }\end{array}$ & $\begin{array}{c}0.22 \\
\pm 0.37\end{array}$ & $\begin{array}{c}0.12 \\
\pm 0.38\end{array}$ & & $\begin{array}{c}0.21 \\
\pm 0.45\end{array}$ & $\begin{array}{c}0.13 \\
\pm 0.30\end{array}$ & & $\begin{array}{c}0.41 \\
\pm 0.51\end{array}$ & $\begin{array}{c}0.01 \\
\pm 0.11\end{array}$ & & - & - & - & - & - & - & \\
\hline
\end{tabular}

${ }^{1}$ SEM = standard error of the mean; ${ }^{2}$ The RMSE is the square root of the variance of the residuals. ${ }^{3}$ Variable is $\ln (x+1)$ transformed. Estimates presented have been transformed back to the original scale. ${ }^{4} \mathrm{NA}=$ not applicable because of $\ln (\mathrm{x}+1)$ or Box-Cox $(B o x$ and Cox 1964) transformation. ${ }^{5}$ Variable is Box-Cox (Box and Cox 1964) transformed. Estimates presented have been transformed back to the original scale. ${ }^{6}$ Variable is not tested statistically; standard deviation is used to show variation.

\section{Discussion}

In contrast to earlier observations of Nisula and Hakkola (1979), the production results (Huuskonen et al. 2010a, $2010 \mathrm{~b}$ ) indicate that bulls can be finished at pasture without impaired animal performance compared to grass silage-based feeding. In the present study there was no significant difference in live weight gain (average 890 and $1529 \mathrm{~g} \mathrm{~d}^{-1}$ in Exp 1 and Exp 2, respectively) during the grazing season or live weight at slaughter (average 620 and $617 \mathrm{~kg}$ in Exp 1 and Exp 2, respectively) between the UB and PAS bulls (Huuskonen et al. 2010a, 2010b). In the present study we show that there were some, but yet quite logical, differences in the behaviour of bulls at pasture and in traditional pens.

Since the UB bulls had no opportunity to graze, the time budgets of foraging behaviour were different between the UB and PAS bulls. The total feeding time was higher in the PAS bulls ( 4.5 hours, grazing and eating concentrates) than in the UB bulls (2.8 hours, eating silage and concentrates). Grazing time in bulls has been previously found to be approximately 10.7 hours $\mathrm{d}^{-1}$ (Hinch et al. 1982). However, the grazing time of the PAS bulls was considerably shorter (approximately 4.0 hours $\mathrm{d}^{-1}$ ), probably because they were offered significant amounts of supplemental concentrates. Unfortunately, Hinch et al. (1982) did not report either the size of paddocks or possible additional feeding. The bulls spent only a short time drinking as was also observed by Tuomisto et al. (2009). The UB bulls tended to spend more time drinking than the PAS bulls which could be due to the fact that the DM content of the grass silage ( 290 and $230 \mathrm{~g} \mathrm{~kg}^{-1}$, Exp 1 and 2, respectively) was higher than that of the grazed grass (139 and 197 $\mathrm{g} \mathrm{kg}^{-1}$, Exp 1 and 2, respectively).

Dietary neutral detergent fibre (NDF) is the component of the diet that is effective in stimulating rumination, and the total chewing time is positively related to the forage NDF intake (Allen 1997). A positive association between the diet NDF content and ruminating time has been widely reported (e.g. Welch and Smith 1970, Nishida et al. 2007). Rinne et al. (1999) reported that time spent ruminating and chewing increases as digestibility of silage decreases and fibre content increases in dairy cows. In the present study, the NDF content of the silage that was offered to the UB bulls was higher (542 and $508 \mathrm{~g} \mathrm{~kg}^{-1} \mathrm{DM}$, Exp 1 and 2, respectively) and the in vitro digestibility was lower (640 and $710 \mathrm{~g} \mathrm{~kg}^{-1} \mathrm{DM}$ ) than the corresponding values for the grazed grass (NDF 404 and $479 \mathrm{~g} \mathrm{~kg}^{-1}$ DM; in vitro digestibility 680 and $730 \mathrm{~g} \mathrm{~kg}^{-1} \mathrm{DM}$ ) (Huuskonen et al. 2010a, 2010b). The different diets with different NDF contents partly explain the difference in the rumination time between the treatments, the UB bulls ruminating more than the PAS bulls.

The higher proportion of walking in the time budget of the PAS bulls compared to the UB bulls was a natural consequence of the larger living area in the pasture. Walking during grazing was not taken into account in our study, and therefore the PAS bulls were actually moving even more than the current results indicate. It has been found that daily exercise has a positive influence on the health (Gustafson 1993) and lying down movements (Gustafson and Lund-Magnussen 1995) of tied dairy cows, and therefore it is likely that also bulls may benefit from increased exercise on pasture. The longer foraging (e.g. grazing) and walking time, and shorter ruminating time in the PAS than the UB bulls explain why the PAS bulls spent less time in a lying posture and more time on their feet than the UB bulls. 
In our study, oral explorative and manipulative behaviour was observed more often in the UB bulls than in the PAS bulls in both instantaneous sampling (sniffing, eating bedding or soil, biting and licking or gnawing structures) and one-zero sampling observations (biting and licking or gnawing structures). Excessive biting and licking objects or wooden material have been considered abnormal behaviour in fattening bulls (Graf 1994). However, it seems that a very variable environment, such as forest vegetation and trees may stimulate oral manipulation of objects in bulls, like gnawing at and masticating bark (Tuomisto et al. 2008). It is possible that the UB bulls manipulated objects more simply because they had the opportunity, i.e. wooden pen structures and bedding were easily available.

In accordance with our PAS results, earlier studies in dairy cows (Redbo 1990) and beef cattle (Ishiwata et al. 2007, Tuomisto et al. 2008) have shown that animals with grazing opportunity have little abnormal oral behaviours. In dairy cattle restricted feeding and restriction of movements by tethering lead up to an average of $13-25 \%$ of daily time spent on tongue rolling (Redbo 1990, 1992, Redbo and Nordblad 1997). The low levels of stereotyped behaviours (less than $0.3 \%$ of observations) in our UB bulls may be explained by unrestricted access to roughage and relatively good freedom of movement (a minimum of $6.4 \mathrm{~m}^{2}$ per animal). Hickey et al. (2003) reported frequencies of stereotyped behaviour from 6.1 to 9.6 events per pen with five steers per four hours in a study with smaller space allowance (1.5-4.0 $\mathrm{m}^{2}$ per animal) than in the present study. Ishiwata et al. (2007) did not find any oral stereotypic behaviour in steers kept in pens with space allowance ranging from 3.6-4.8 $\mathrm{m}^{2}$ per animal. However, the comparison of the results from these two studies to our results is difficult because of differences in the observation methods, classification of stereotyped behaviour and way of presenting results.

There was no difference between the UB and PAS bulls in self-grooming using the tongue, but the UB bulls spent more time rubbing than the PAS bulls. Also Babu et al. (2004) found a similar frequency for self-grooming among calves in different housing conditions. Earlier studies have shown that cattle readily utilise opportunities for scratching and rubbing provided by mechanical brushes, live trees and devices specially designed for grooming (DeVries et al. 2007, Kohari et al. 2007). Rubbing opportunities for the PAS bulls in our study were very limited: there were no trees in the pasture and the only structures which could be used for scratching and rubbing were the water tank and the feeding trough which were placed in the other end of the paddock. On the other hand, the rubbing opportunities were greater in the uninsulated barn. Wooden pen structures e.g. a horizontal neck bar above the feeding trough and vertical bars supporting the walls were easily available for rubbing at any time.

Earlier studies report a decrease in agonistic behaviour in female cattle and steers when living space has been expanded, i.e. when the space allowance has been increased, or when the behaviour of animals at pasture and in close confinement in a cubicle house has been compared (Kondo et al. 1989, O'Connell et al. 1989, Miller and Wood-Gush 1991). However, in our study, the more spacious pasture environment did not result in a decrease in butting in PAS bulls (measured in either instantaneous or one-zero sampling) compared to the UB bulls with a much lower space allowance. These results are in agreement with our previous observations in growing bulls housed in an uninsulated barn or in extensive forest paddocks (Tuomisto et al. 2008, 2009). It should be noted that in our study the space allowance per bull in the uninsulated barn was relatively high, because it was desired to avoid very crowded conditions and insufficient lying area (see e.g. Ingvartsen and Andersen 1993, Nielsen et al. 1997). Due to the relatively high space allowance the UB bulls may have encountered agonistic behaviour less than would have been observed in more crowded conditions.

While instantaneous sampling results revealed no differences between the groups of bulls in social licking and other social behaviour (e.g. sniffing another animal and sexual behaviour), one-zero sampling observations indicated that social licking was performed more by UB bulls than by PAS bulls, and that mounting was performed more by PAS bulls than by UB bulls. Methodologically, this shows the power of one-zero sampling in analysing intermittent behaviour (c.f. Martin and Bateson 1993). The explanation for the higher amount of social licking in the UB bulls is not clear. Due to the lower space allowance in the uninsulated barn there probably were more violations of the bulls' individual space, and allogrooming may have functioned to reduce tension between the UB bulls (see Sato et al. 1993). Different surface materials may explain why the PAS bulls performed more mounting than the UB bulls. Ruis-Heutinck et al. (2000) found that bulls on soft bedding showed more mounting and stretching and less slipping than bulls on concrete slatted floors. Similarly, in our study the UB bulls may have hesitated to perform mounting on the possibly slippery concrete part of the pen floor.

There were several statistically significant differences or tendencies to differ in the bulls' behaviours between Exp 1 and Exp 2. There was more (in either or both instantaneous sampling and one-zero sampling observations) oral explorative and manipulative behaviour (sniffing, eating bedding or soil, biting and licking or gnawing structures), social licking, mounting, rubbing, walking and butting in Exp 1. The breed affects the temperament of cattle (e.g. Murphey et al. 1980, Boivin et al. 1994) but breed effects on grazing behaviour have been studied less (see a review in Fraser et al. [2009]). 
Our results may indicate that the breed of the bulls could influence their behaviour, i.e. dairy bulls (Exp 1) were generally more active than beef bulls (Exp 2 ) and may have had a stronger reaction to the increased social pressure created by relatively restricted feeding space in the uninsulated barn. However, although the housing conditions in Exp 1 and Exp 2 were kept as similar as possible, the effect of weather conditions during the behavioural observations (c.f. Hinch et al. 1982), feed quality, etc. cannot be fully ruled out as causes of differences between Exp 1 and Exp 2 .

\section{Conclusions}

Overall, our behavioural study revealed only minor differences in time budgets between the two housing environments. There were no differences in drinking, social licking, butting, other social behaviour, self-licking idling or stereotyped tongue rolling between the UB and PAS bulls. The UB bulls spent more time in lying, ruminating, oral explorative and manipulative behaviour and rubbing and less time foraging and walking than the PAS bulls. The UB bulls performed more social licking and oral manipulation of objects and less mounting than the PAS bulls. These differences resulted most probably from the different feeding regimes and different space allowances.

\section{Acknowledgements}

Financial support from the Employment and Economic Development Centre for Northern Ostrobothnia, INTERREG IIIA North Programme (the Interreg Programmes are financed by the European Regional Development Fund), the State Provincial Office of Lapland, the Regional Council of Lapland, the Finnish Ministry of Agriculture and Forestry and the Finnish Cultural Foundation, North Savo Regional fund is gratefully acknowledged. The authors would like to thank Ms Susanna Järvikylä and Mr Sami Huttu for technical assistance and Mr Matti Huumonen with his staff for excellent care of the experimental animals. The authors wish to express their gratitude also to Mr Lauri Jauhiainen and Ms Maarit Hyrkäs for advice on the statistical analyses. The evaluation of the manuscript by Professor Marketta Rinne is warmly acknowledged.

\section{References}

Absmanner, E., Rouha-Mülleder, C., Scharl, T., Leisch, F. \& Troxler, J. 2009. Effects of different housing systems on the behaviour of beef bulls - An on-farm assessment on Austrian farms. Applied Animal Behaviour Science 118: 12-19.

Allen, M.S. 1997. Relationship between fermentation acid production in the rumen and the requirement for physically effective fiber. Journal of Dairy Science 80: 1447-1462.

Babu, L.K., Pandey, H.N. \& Sahoo, A. 2004. Effect of individual versus group rearing on ethological and physiological responses of crossbred calves. Applied Animal Behaviour Science 87: 177-191.

Boivin, X., Le Neindre, P., Garel, J.P. \& Chupin, J.M. 1994. Influence of breed and rearing management on cattle reactions during human handling. Applied Animal Behaviour Science 39: 115-122.

Box, G.E.P. \& Cox, D.R. 1964. An analysis of transformations. Journal of the Royal Statistical Society: Series B 26: $211-252$.

DeVries, T.J., Vankova, M., Veira, D.M. \& von Keyserlingk, M.A.G. 2007. Usage of mechanical brushes by lactating dairy cows. Journal of Dairy Science 90: 2241-2245.

Fraser, M.D., Davies, D.A., Vale, J.E., Nute, G.R., Hallet K.G., Richardson, R.I. \& Wright, I.A. 2009. Performance and meat quality of native and continental cross steers grazing improved upland pasture or semi-natural rough grazing. Livestock Science 123 : 70-82.

Graf, B. 1994. Abnormal oral behaviours in fattening bulls: incidence, causation and implications. Applied Animal Behaviour Science 40: 79-80.

Gustafson, G.M. 1993. Effects of daily exercise on the health of tied dairy cows. Preventive Veterinary Medicine 17: $209-223$

Gustafson, G.M. \& Lund-Magnussen, E. 1995. Effect of daily exercise on the getting up and lying down behaviour of tied dairy cows. Preventive Veterinary Medicine 25: 27-36.

Hickey, M.C., Earley, B. \& Fisher, A.D. 2003. The effect of floor type and space allowance on welfare indicators of finishing steers. Irish Journal of Agricultural and Food Research 42: 89-100.

Hinch, G.N., Thwaites, C.J. \& Lynch, J.J. 1982. A note on the grazing behaviour of young bulls and steers. Animal Production 35: 289-291.

Huuskonen, A., Jansson, S., Honkavaara, M., Tuomisto, L. \& Kauppinen, R. 2010a. Performance, meat fatty acid profile and meat colour of dairy bulls finished on grazed pasture or grass silage-based diets with similar concentrate allowances. Acta Agriculturae Scandinavica, Section A, Animal Science 60: 104-111.

Huuskonen, A., Jansson, S., Honkavaara, M., Tuomisto, L., Kauppinen, R. \& Joki-Tokola, E. 2010b. Meat colour, fatty acid profile and carcass characteristics of Hereford bulls finished on grazed pasture or grass silage-based diets with similar concentrate allowance. Livestock Science 131: 125-129.

Ingvartsen, K.L. \& Andersen, H.R. 1993. Space allowance and type of housing for growing cattle. A review of performance and possible relation to neuroendocrine function. Acta Agriculturae Scandinavica, Section A, Animal Science 43: 65-80. 
Ishiwata, T., Uetake, K., Kilgour R.J., Eguchi, Y. \& Tanaka, T. 2007. Oral behaviours of beef steers in pen and pasture environments. Journal of Applied Animal Welfare Science 10: 185-192.

Kilgour, R. \& Campin, D.N. 1973. The behaviour of entire bulls of different ages at pasture. Proceedings of the New Zealand Society of Animal Production 33: 125-133.

Kohari, D., Kosako, T., Fukasawa, M. \& Tsukada, H. 2007. Effect of environmental enrichment by providing trees as rubbing objects in grassland: Grazing cattle need tree-grooming. Animal Science Journal 78: 413-416.

Kondo, S., Sekine, J., Okubo, M. \& Asahida, Y. 1989. The effect of group size and space allowance on the agonistic and spacing behavior of cattle. Applied Animal Behaviour Science 24: 127-135.

Krohn, C.C., Munksgaard, L. \& Jonasen, B. 1992. Behaviour of dairy cows kept in extensive (loose housing/pasture) or intensive (tie stall) environments. I. Experimental procedure, facilities, time budgets - diurnal and seasonal conditions. Applied Animal Behaviour Science 34: 37-47.

Martin, P. \& Bateson, P. 1993. Measuring behaviour, An introductory guide. 2nd edition. Cambridge University Press, Cambridge, United Kingdom. 222p.

Martiskainen, P., Tuomisto, L., Huuskonen, A. \& Mononen, J. 2008. Training dairy bull calves to stay within light-build electric fences. Agricultural and Food Science 17: 121-126.

Miller, K. \& Wood-Gush, D.G.M. 1991. Some effects of housing on the social behaviour of dairy cows. Animal Production 53: 271-278.

Murphey, R.M., Moura Duarte, F.A. \& Torres Penedo, M.C. 1980. Approachability of bovine cattle in pastures: breed comparisons and a breed $\times$ treatment analysis. Behavior Genetics 10: 171-181.

Nielsen, L.H., Mogensen, L., Krohn, C., Hindhede, J. \& Sørensen, J.T. 1997. Resting and social behaviour of dairy heifers housed in slatted floor pens with different sized bedded lying areas. Applied Animal Behaviour Science 54: 307-316.

Nishida, T., Eruden, B., Hosoda, K., Matsuyama, H., Xu, C. \& Shioya, S. 2007. Digestibility, methane production and chewing activity of steers fed whole-crop round bale corn silage preserved at three maturities. Animal Feed Science and Technology 135: 42-51.

Nisula, H. \& Hakkola, H. 1979. Lihanautojen määrän vaikutus laitumen satoon. Kehittyvä Maatalous 42: 12-22. (In Finnish.)

O'Connell, J., Giller, P.S. \& Meaney, W. 1989. A comparison of dairy cattle behavioural patterns at pasture and during confinement. Irish Journal of Agricultural Research 28: 65-72.

Redbo, I. 1990. Changes in duration and frequency of stereotypies and their adjoining behaviours in heifers, before, during and after the grazing period. Applied Animal Behaviour Science 26: 57-67.

Redbo, I. 1992. The influence of restraint on the occurrence of oral stereotypies in dairy cows. Applied Animal Behaviour Science 35: 115-123.

Redbo, I. \& Nordblad, A. 1997 Stereotypies in heifers are affected by feeding regime. Applied Animal Behaviour Science 53: 193-202.

Rinne, M., Jaakkola, S., Kaustell, K., Heikkilä, T. \& Huhtanen, P. 1999. Silages harvested at different stages of grass growth versus concentrate foods as energy and protein sources in milk production. Animal Science 69: 251-263.

Rueda, B.L., Blake, R.W., Nicholson, C.F., Fox, D.G., Tedeschi, L.O., Pell, A.N., Fernandes, E.C.M., Valentim, J.F. \& Carneiro, J.C. 2003. Production and economic potentials of cattle in pasture-based systems of the western Amazon region of Brazil. Journal of Animal Science 81: 2923-2937.

Ruis-Heutinck, L.F.M., Smits, M.C.J., Smits, A.C. \& Heeres, J.J. 2000. Effects of floor type and floor area on behaviour and carpal joint lesions in beef bulls. In: Proceedings of sessions of the European Association for Animal Production commission on animal management and health. The Hague, the Netherlands. p. 29-36.

Sato, S., Tarumizu, K. \& Hatae, K. 1993. The influence of social factors on allogrooming in cows. Applied Animal Behaviour Science 38: 235-244.

Schrader, L., Roth, H.-R., Winterling, C., Brodmann, N., Langhans, W., Geyer, H. \& Graf, B. 2001. The occurrence of tail tip alterations in fattening bulls kept under different husbandry conditions. Animal Welfare 10: 119-130.

Sørensen, J.T., Sandøe, P. \& Halberg, N. 2001. Animal welfare as one among several values to be considered at farm level: the idea of an ethical account for livestock farming. Acta Agriculturae Scandinavica, Section A, Animal Science, Supplement 30: 11-16.

Tuomisto, L., Ahola, L., Martiskainen, P., Kauppinen, R. \& Huuskonen, A. 2008. Comparison of time budgets of growing Hereford bulls in an uninsulated barn and in extensive forest paddocks. Livestock Science 118: 44-52.

Tuomisto, L., Huuskonen, A., Ahola, L. \& Kauppinen, R. 2009. Different housing systems for growing dairy bulls in Northern Finland - effects on performance, behaviour and immune status. Acta Agriculturae Scandinavica, Section A, Animal Science 59: 35-47.

Welch, J.G. \& Smith, A.M. 1970. Forage quality and rumination time in cattle. Journal of Dairy Science 53: 797-800. 